\title{
Osmotic Potential, Sucrose Level, and Activity of Sucrose Metabolic Enzymes in Tall Fescue in Response to Deficit Irrigation
}

\author{
Jinmin $\mathbf{F u} \mathbf{u}^{\mathbf{1}}$ \\ Key Laboratory of Plant Germplasm Enhancement and Specialty Agriculture, Wuhan Botanical \\ Garden, Chinese Academy of Science, Wuhan City, Hubei, 430074, P.R. China
}

Bingru Huang

Department of Plant Biology and Pathology, Rutgers University, New Brunswick, NJ 08901

Jack Fry

Department of Horticulture, Forestry and Recreation Resources, Kansas State University, Manhattan, KS 66506

\begin{abstract}
AdDitional InDEX wORDs. carbohydrate, sucrose phosphate synthase, sucrose synthase, acid invertase, Festuca arundinacea
ABstract. Effects of deficit irrigation applied to home lawns, used as means of water conservation, are an important issue. However, the impact of deficit irrigation on sucrose metabolism in tall fescue (Festuca arundinacea) is unknown and important because sucrose is the dominant form of carbohydrate transported to developing plant organs. The objectives of this study were to investigate the effects of deficit irrigation on leaf water content, osmotic potential $\left(\psi_{\mathrm{S}}\right)$, sucrose level, and the activity of sucrose phosphate synthase (SPS; EC 2.4.1.14), sucrose synthase (SS; EC 2.4.1.13), and acid invertase (AI; EC 3.2.1.26) in tall fescue leaves. Sods of 'Falcon II' tall fescue were established in polyvinylchloride $(P V C)$ tubes $(10 \mathrm{~cm}$ diameter $\times 40 \mathrm{~cm}$ long) filled with a mixture of sand and fritted clay [9:1 (v:v)] and then placed in growth chambers. Reference evapotranspiration rate [ETo (millimeters of water per day)] was determined by weighing the PVC tubes containing well-watered turfgrass every 3 days to determine water loss on a daily basis as ETo. Deficit irrigation treatments were applied as follows: well-watered control, mild drought stress $(60 \%$ ETo), and severe drought stress $(20 \%$ ETo). Leaf water content was lower at 6, 12, and 20 days of treatment for the $20 \%$ ETo treatment and 20 days after treatment began for the $60 \%$ ETo treatment. Compared with the wellwatered control, $\psi_{S}$ was lower in the $60 \%$ ETo treatment on all three measurement dates. Sucrose was higher at 8 and 14 days after treatment began in the $60 \%$ ETo treatment and on all three measurement dates in the $20 \%$ ETo treatment relative to the well-watered control. No difference in sucrose level was observed between the $20 \%$ ETo and $60 \%$ ETo irrigation regimes at 8 and 14 days of treatment. Beginning 14 days after treatment, tall fescue had a higher level of SPS in the $60 \%$ ETo and $20 \%$ ETo treatments compared with the well-watered treatment. Tall fescue receiving $60 \%$ or $20 \%$ ETo had a lower level of AI activity on all measurement dates. Results suggest that the decrease in $\psi_{\mathrm{S}}$ was accompanied by higher sucrose levels, which were the result of the increased level of SPS and SS activity and a decline in AI activity.
\end{abstract}

Proper irrigation management is critical to growing quality turfgrass with limited water in arid and semiarid regions. Deficit irrigation, defined as applying water in amounts less than the reference evapotranspiration rate, is an irrigation management practice that could result in water savings (Fu et al., 2007). The ETo, measured as amount of daily water loss from a canopy under non-water-limiting conditions, often is used to estimate water requirements in turfgrass irrigation. Reduction in irrigation application not only can reduce costs associated with water consumption and can improve environmental stress tolerance, but it also prevents turfgrass from the injury of mechanical stresses, cyanobacteria, and diseases (Beard, 1973; Dernoeden, 2002; Turgeon, 2008).

Some researchers have found that turfgrass is able to tolerate moderate drought (DaCosta and Huang, 2006; Fu et al., 2004; Gilbeault et al., 1985). Tall fescue, bermudagrass (Cynodon dactylon), and zoysiagrass (Zoysia japonica) irrigated to $60 \%$ or $80 \%$ of ETo exhibited similar turfgrass quality when

Received for publication 16 June 2010. Accepted for publication 24 Sept. 2010 ${ }^{1}$ Corresponding author. E-mail: huang@aesop.rutgers.edu. compared with well-watered turfgrass (Fu et al., 2004). Gilbeault et al. (1985) also observed that tall fescue, kentucky bluegrass (Poa pratensis), and perennial ryegrass (Lolium perenne) had only a slightly lower level of quality when irrigated at $80 \%$ ETo relative to $100 \%$ ETo.

Availability of total nonstructural carbohydrate (TNC) has been widely used as a physiological measure of stress tolerance, because carbohydrates provide energy and solutes for osmotic adjustment. Sucrose, an important component of TNC, is the dominant form of carbohydrate transported to developing plant organs and is one of the sugars stored in higher plants (Khayat and Zieslin, 1987). Sucrose also serves as an osmotic solute (Premachandra et al., 1992; Rekika et al., 1998; Tan et al., 1992; Zhang and Archbold, 1993). The effect of water deficits on sucrose levels has been reported in some plants. For example, improved responses of bean (Phaseolus vulgaris) to water deficits were associated with sucrose metabolism (Castrillo, 1992; Vassey et al., 1991). McManus et al. (2000) found that after white clover (Trifolium repens) was exposed to a period of moderate drought stress, leaf sucrose content increased significantly. Leaf sucrose level increased by $300 \%$ at the end of an 
8-d-long drought period in sugarbeet (Beta vulgaris) (Harn and Daie, 1992).

Because sucrose may serve an important role in drought tolerance, understanding the enzyme activity affecting sucrose metabolism is critical. Sucrose synthesis can be regulated by rapid changes in the activity of sucrose phosphate synthase, sucrose synthase, and acid invertase (Castrillo, 1992; Hawker, 1985; Huber and Huber, 1996). Sucrose phosphate synthase catalyzes the synthesis of sucrose-phosphate from uracildiphosphate (UDP)-glucose and fructose-6-phosphate, and this reaction occurs predominantly in the cytosol of sucrose-source leaf tissue. Leaf SPS activity is often correlated with the rate of sucrose synthesis and export (Huber and Israel, 1982; Rocher et al., 1989; Stitt et al., 1988). Some researchers found that water deficits lead to an increase in SPS activity in potato tubers [Solanum tuberosum (Geigenberger et al., 1997)], soybean leaves [Glycine max (Cheikh and Brenner, 1992)], and pigeonpea leaves [Cajanus cajan (Keller and Ludlow, 1993)]. However, Castrillo (1992) reported that the values of total (substrate-saturating conditions) and Pi-insensitive (substrate limiting conditions plus inorganic phosphate) SPS activity in $P$. vulgaris were reduced by drought stress. These conflicting results suggest that effects of drought stress on SPS activity depend on experimental conditions. Sucrose synthase catalyzes both the synthesis and cleavage of sucrose. Yang et al. (2001) reported that water deficits enhanced SS activity in the cleavage direction, but the activity of SS in the synthesis direction was not measured. Castrillo (1992) reported that the synthesis activity of SS was increased by water deficit. In contrast, the effects of drought on AI appear to be negative. AI catalyzes the hydrolysis of sucrose into glucose and fructose. Dorion et al. (1996) observed that the activity of soluble AI in wheat (Triticum aestivum) declined fourfold during a drought stress period and never recovered.

Effects of drought stress on sucrose metabolism have been examined intensively, mainly in annual crops, as discussed previously. However, how different levels of deficit irrigation influence sucrose metabolism and associated enzymes are not well understood, because plants are often subjected to different levels of irrigation regimes or levels of drought stress. The objectives of this study were to address the question by examining the influence of deficit irrigation on leaf $\psi_{\mathrm{S}}$, sucrose level, and sucrose metabolic enzymes in a cool-season grass species, tall fescue. This species is a widely used species as turfgrass, which has superior drought resistance to many other cool-season grass species (Fry and Huang, 2004). Tall fescue is widely used in temperate climates, because it tolerates heat and drought well compared with other cool-season turfgrasses (Fry and Huang, 2004). Greater knowledge of these responses might provide insights into drought resistance mechanisms of coolseason grass species in areas with varying irrigation availability.

\section{Materials and Methods}

Plant growth conditions. Sod pieces of 'Falcon II' tall fescue were collected from the field on 4 Nov. 2001 and planted on a mixture of sand and fritted clay [9:1 (v:v); Profile Products, Deerfield, IL] contained in PVC tubes $(10 \mathrm{~cm}$ diameter $\times 40 \mathrm{~cm}$ long). The grasses were grown for $\approx 90 \mathrm{~d}$ in growth chambers with a temperature of $25 / 20{ }^{\circ} \mathrm{C}$ (day/night) and a 14-h photoperiod with a photosynthetic active radiation of 400 $\mu \mathrm{mol} \cdot \mathrm{m}^{-2} \cdot \mathrm{s}^{-1}$. During the 90 -d period of plant establishment, the turfgrass was well irrigated until drainage occurred from the bottom of the containers. It was fertilized weekly with halfstrength Hoagland's solution (Hoagland and Arnon, 1950), and it was mowed every other day at a 5 to $6 \mathrm{~cm}$ height with an electric clipper.

IRRIGATION TREATMENTS AND EXPERIMENTAL DESIGN. The tall fescue was subjected to three irrigation regimes: 1) fully irrigated control to replace $100 \%$ water loss measured as ETo; 2) moderate deficit irrigation to replace $60 \%$ of ETo; and 3) severe deficit irrigation to replace $20 \%$ of ETo. Reference evapotranspiration rate was measured using the water balance method described by $\mathrm{Fu}$ et al. (2004). It was determined by weighing, between 0900 and $1000 \mathrm{HR}$, PVC tubes containing well-watered turfgrass at $3 \mathrm{~d}$ after treatment began to determine daily water loss (expressed as millimeters per day ETo). For the different irrigation regimes, the amount of water needed to provide $20 \%, 60 \%$, or $100 \%$ of ETo was added to each container corresponding to each treatment. Reference evapotranspiration was measured and the amount of water needed was added to each container every other $3 \mathrm{~d}$ based on the previously described methods. The study was set up as a randomized block design. Each treatment was replicated four times with one replication in each growth chamber (Conviron, Winnipeg, Canada).

Measurements. To measure leaf water content (LWC), $\approx 0.5 \mathrm{~g}$ of fresh leaves was collected and weighed immediately. Then, the leaf samples were killed at $105^{\circ} \mathrm{C}$, dried at $75^{\circ} \mathrm{C}$ in a convection oven until the sample weight became constant, and reweighed. Leaf water content was calculated based on the difference between leaf fresh weight and dry weight. Dry leaves were used for sugar analysis.

Leaf $\psi_{\mathrm{S}}$ was measured on fully expanded fresh leaves using the method described by Qian and Fry (1997). Excised fresh leaves were placed in a microcentrifuge tube, immediately frozen in liquid nitrogen, and stored in $-20{ }^{\circ} \mathrm{C}$ until analyzed. Frozen leaves were thawed for $30 \mathrm{~min}$ and cell sap was pressed using a laboratory press (Fred S. Carver, Wabash, IN). A 10- $\mu \mathrm{L}$ aliquot of the expressed sap was injected onto a filter paper disc that was placed in the sampling chamber of an osmometer (Wescor, Logan, UT). Osmolarity of cell sap was converted from millimoles per kilogram to $\psi_{\mathrm{S}}$ (megapascals) using the formula: $\mathrm{MPa}=-\mathrm{c} \times 2.58 \times 10^{-3}$, where $\mathrm{c}$ is osmolarity (millimoles per kilogram).

Concentration of sucrose was determined using the method of Liu and Huang (2000). Dry leaves were incubated in $10 \mathrm{~mL}$ $0.1 \mathrm{M}$ phosphate buffer ( $\mathrm{pH} 5.4$ ) for $24 \mathrm{~h}$ at $22{ }^{\circ} \mathrm{C}$. A $0.2-\mathrm{mL}$ sample of supernatant was mixed with $1.0 \mathrm{~mL}$ invertase $(10 \mathrm{U} /$ $\mathrm{mL}$ ) or distilled water and incubated in a water bath for $1 \mathrm{~h}$ at 50 ${ }^{\circ} \mathrm{C}$. The difference in reducing sugar concentrations between the incubation solution with and without invertase was used to calculate sucrose concentration (Ting, 1956). The amount of reducing sugar was determined using the method of Ting (1956). One milliliter of the extraction solution was transferred to a $100-\mathrm{mL}$ flask, and $5 \mathrm{~mL}$ of ferricyanide reagent was added. Flasks were the placed in a boiling water bath for $10 \mathrm{~min}$. After heating, the flasks were cooled quickly in running water. The solutions were neutralized partially with $10 \mathrm{~mL}$ of a $1 \mathrm{M} \mathrm{H}_{2} \mathrm{SO}_{4}$ solution and mixed thoroughly until no more gas was evolved. Four milliliters of arsenomolybdate were added, and solutions were mixed again and then diluted to volume. The absorbance of the solution was measured at $515 \mathrm{~nm}$ with a spectrophotometer (Spectronic Instruments, Rochester, NY). The amount of 
sugar in the solution was calculated using a glucose standard curve as described by Ting (1956).

For enzyme analysis, 0.5 -g fresh leaf samples were placed in liquid nitrogen and stored in a freezer at $-80{ }^{\circ} \mathrm{C}$. To extract enzymes, frozen leaf samples were ground to powder using a mortar and pestle in liquid nitrogen. To the ground sample was added $5 \mathrm{~mL}$ of extraction medium containing $50 \mathrm{~mm}$ Hepes-NaOH buffer ( $\mathrm{pH} 7.5$ ), $0.5 \mathrm{~mm} \mathrm{MgCl}_{2}, 1 \mathrm{~mm} \mathrm{Na}_{2}$ EDTA, $2 \mathrm{~mm}$ diethyldithiocarbamic acid, $2.5 \mathrm{~mm}$ dithiothreitol, 1\% bovine serum albumin, and $2 \%$ polyvinylpyrrolidone. The extract was centrifuged for $20 \mathrm{~min}$ at $12,000 \mathrm{~g}_{\mathrm{n}}$. The supernatant was assayed for SPS, SS, and AI activity. Sucrose synthase catalyzes both sucrose synthesis and sucrose degradation. The catalytic activity of SS for sucrose synthesis was measured using glucose and fructose as a substrate for the enzyme. Assays for SPS and SS were performed by incubating $(70 \mu \mathrm{L})$ tissue extracts for $30 \mathrm{~min}$ at $37^{\circ} \mathrm{C}$ with an equal volume of reaction mixture according to Khayat and Zieslin (1987). The SPS assay contained $15 \mathrm{~mm}$ UDP-glucose, $15 \mathrm{~mm}$ fructose 6-P, $5 \mathrm{~mm}$ $\mathrm{MgCl}_{2}-6 \mathrm{H}_{2} \mathrm{O}, 5 \mathrm{~mm} \mathrm{NaF}, 5 \mathrm{~mm} \mathrm{Na} 2 \mathrm{MoO}_{4} \cdot 2 \mathrm{H}_{2} \mathrm{O}$, and $50 \mathrm{~mm}$ Hepes-NaOH buffer ( $\mathrm{pH} 7.5$ ). For the SS assay, fructose 6-P was replaced by fructose. The reaction was ended by the addition of $70 \mu \mathrm{L}$ of $1 \mathrm{~N} \mathrm{NaOH}$, and sucrose formation was determined by the resorcinol colorimetric method (Rufty and Huber, 1983). Enzymatic activity was determined by reference to a blank reaction mixture without UDP. Acid invertase activity was determined according to Khayat and Zieslin (1987). Aliquots $(200 \mu \mathrm{L})$ of plant extracts were incubated for $30 \mathrm{~min}$ at $37^{\circ} \mathrm{C}$ with an equal quantity of $1 \mathrm{M}$ sucrose and $600 \mu \mathrm{L}$ phosphate citrate buffer ( $\mathrm{pH}$ 5.0). The reaction was ended by the addition of $1 \mathrm{~mL}$ of Sumner reagent (containing $8.8 \mathrm{~g}$ of iron $\mathrm{SO}_{4} \cdot 7 \mathrm{H}_{2} \mathrm{O}$ in $100 \mathrm{~mL} 3.75 \mathrm{M}$ sulfuric acid and 900 $\mathrm{mL}$ of water) (Sumner, 1925). Enzyme blanks were incubated in Sumner reagent. Activity was expressed as the quantities of reducing sugars (i.e., micromoles of sucrose per gram fresh weight per hour) formed by sucrose hydrolysis (Khayat and Zieslin, 1987). Levels of SPS, SS, and AI were expressed as micromoles sucrose per gram fresh weight per hour.

Statistical analysis. Treatment effects were determined by analysis of variance using the general linear model procedure of SAS (Version 9.1.3; SAS Institute, Cary, NC). Mean separation was performed using Fisher's protected least significant difference test $(P \leq 0.05)$. The analysis of variance revealed an interaction between irrigation levels and sampling dates. Therefore, data from each date are shown separately.

\section{Results}

Compared with the well-watered regime, LWC was lower on all three dates for tall fescue subjected to the $20 \%$ ETo irrigation level and lower at $20 \mathrm{~d}$ after treatment began for the $60 \%$ ETo irrigated level (Table 1). Osmotic potential was lower in the $20 \%$ or $60 \%$ ETo treatment compared with the wellwatered control on all three measurement dates. Among the three irrigation regimes, the lowest level of $\psi_{\mathrm{S}}$ was found in the $20 \%$ ETo treatment. When measured at $20 \mathrm{~d}$ of treatment, $\psi_{\mathrm{S}}$ was $36.6 \%$ and $171.4 \%$ lower in the $60 \%$ or $20 \%$ ETo treatments, respectively, relative to the well-watered tall fescue.

For the $60 \%$ or $20 \%$ ETo treatment $8 \mathrm{~d}$ after irrigation water was withheld, sucrose content in tall fescue leaves increased above that in the well-watered control (Fig. 1). When measured
Table 1. Leaf water content and osmotic potential in 'Falcon II' tall fescue subjected to three irrigation levels.

\begin{tabular}{|c|c|c|c|}
\hline \multirow{3}{*}{$\begin{array}{l}\text { Irrigation } \\
(\% \text { ETo })^{z}\end{array}$} & \multicolumn{3}{|c|}{ Duration of irrigation treatment (d) } \\
\hline & 6 & 12 & 20 \\
\hline & \multicolumn{3}{|c|}{ Leaf water content $(\%)$} \\
\hline 100 & $73.3 \mathrm{a}^{\mathrm{y}}$ & $72.7 \mathrm{a}$ & $72.7 \mathrm{a}$ \\
\hline 60 & $70.8 \mathrm{a}$ & $70.0 \mathrm{a}$ & $68.3 \mathrm{~b}$ \\
\hline \multirow[t]{2}{*}{20} & $60.1 \mathrm{~b}$ & $54.5 \mathrm{~b}$ & $58.9 \mathrm{c}$ \\
\hline & \multicolumn{3}{|c|}{ Osmotic potential (MPa) } \\
\hline 100 & $-1.95 \mathrm{c}$ & $-1.76 \mathrm{c}$ & $-1.75 \mathrm{c}$ \\
\hline 60 & $-2.21 b$ & $-2.31 \mathrm{~b}$ & $-2.39 \mathrm{~b}$ \\
\hline 20 & $-3.03 \mathrm{a}$ & $-4.49 \mathrm{a}$ & $-4.75 a$ \\
\hline
\end{tabular}

${ }^{\mathrm{z}}$ Reference evapotranspiration (ETo) of well-watered turfgrass.

${ }^{y}$ Means in a column for each day followed by the same letter are not significantly different based on Fisher's protected least significant difference test at $P \leq 0.05$.

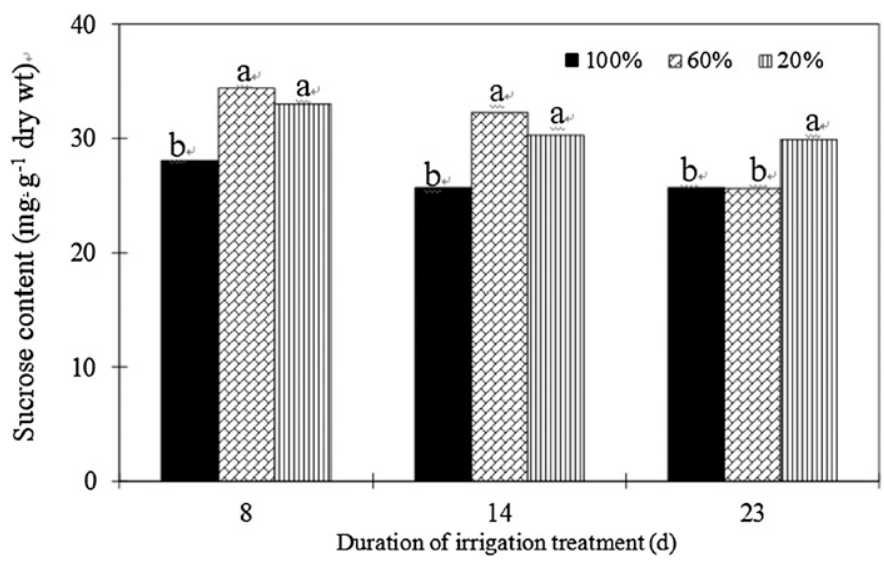

Fig. 1. Sucrose content in 'Falcon II' tall fescue leaves subjected to $20 \%, 60 \%$, or $100 \%$ of reference evapotranspiration. Means in a column for each day followed by the same letter are not significantly different based on Fisher's protected least significant difference test at $P \leq 0.05$.

at $23 \mathrm{~d}$ of treatment, sucrose content in the plants subjected to the $60 \%$ ETo irrigation declined to a level similar to the wellwatered control. However, at $23 \mathrm{~d}$ of treatment, sucrose content was $16.3 \%$ higher in $20 \%$ ETo treatment when compared with the well-watered control.

The enzymes involved in the metabolism of sucrose were also affected by the irrigation treatment. The tall fescue subjected to the $60 \%$ ETo irrigation and the $20 \%$ ETo irrigation exhibited an activity of SPS and SS that was similar at $8 \mathrm{~d}$ of treatment; however, leaves from the same treatment had higher SPS and SS activity levels at 14 and $23 \mathrm{~d}$ of treatment relative to the well-watered control (Table 2). At $23 \mathrm{~d}$ of treatment, SPS level was $26.3 \%$ higher in the $20 \%$ ETo treatment and $9.0 \%$ higher in the $60 \%$ ETo treatment relative to the well-watered control, respectively. Tall fescue subjected to $23 \mathrm{~d}$ of $20 \%$ and $60 \%$ ETo treatments exhibited an $11.3 \%$ and $16.6 \%$ higher SS activity, respectively, compared with the well-watered plants (Table 2). On all three measurement dates, AI activity was lower in the $20 \%$ or $60 \%$ ETo treatment relative to the wellwatered control (Table 2). At $23 \mathrm{~d}$ of treatment, AI activity was $6.3 \%$ and $16.1 \%$ lower in the $60 \%$ and $20 \%$ ETo treatments, respectively, than that of the well-watered control. 
Table 2. Activity of sucrose phosphate synthase (SPS), sucrose synthase (SS), and acid invertase (AI) in 'Falcon II' tall fescue leaves subjected to three irrigation levels.

\begin{tabular}{|c|c|c|c|}
\hline \multirow{3}{*}{$\begin{array}{l}\text { Irrigation } \\
(\% \text { ETo })^{z}\end{array}$} & \multicolumn{3}{|c|}{ Duration of irrigation treatment $(\mathrm{d})$} \\
\hline & 8 & 14 & 23 \\
\hline & \multicolumn{3}{|c|}{ SPS activity [sucrose $\left(\mu \mathrm{mol} \cdot \mathrm{g}^{-1}\right.$ fresh wt per hour $)$} \\
\hline 100 & $256.0 \mathrm{a}^{\mathrm{y}}$ & $198.3 \mathrm{~b}$ & $220.2 \mathrm{c}$ \\
\hline 60 & $231.1 \mathrm{a}$ & $235.3 \mathrm{a}$ & $240.1 \mathrm{~b}$ \\
\hline \multirow[t]{2}{*}{20} & $232.9 \mathrm{a}$ & $246.3 \mathrm{a}$ & $278.1 \mathrm{a}$ \\
\hline & \multicolumn{3}{|c|}{$\mathrm{SS}$ activity [sucrose $\left(\mu \mathrm{mol} \cdot \mathrm{g}^{-1}\right.$ fresh wt per hour $\left.)\right]$} \\
\hline 100 & $208.9 \mathrm{a}$ & $165.9 \mathrm{c}$ & $228.6 \mathrm{~b}$ \\
\hline 60 & $186.3 \mathrm{a}$ & $248.3 \mathrm{a}$ & $254.5 \mathrm{a}$ \\
\hline \multirow[t]{2}{*}{20} & $186.7 \mathrm{a}$ & $199.0 \mathrm{~b}$ & $266.5 \mathrm{a}$ \\
\hline & \multicolumn{3}{|c|}{ AI activity [sucrose $\left(\mu \mathrm{mol} \cdot \mathrm{g}^{-1}\right.$ fresh wt per hour $\left.)\right]$} \\
\hline 100 & $66.6 \mathrm{a}$ & $55.1 \mathrm{a}$ & $57.3 \mathrm{a}$ \\
\hline 60 & $58.9 \mathrm{~b}$ & $47.0 \mathrm{~b}$ & $53.7 \mathrm{~b}$ \\
\hline 20 & $42.3 \mathrm{c}$ & $39.7 \mathrm{c}$ & $48.1 \mathrm{c}$ \\
\hline
\end{tabular}

${ }^{\mathrm{z}}$ Reference evapotranspiration (ETo) of well-watered turfgrass.

${ }^{y}$ Means in a column for each day followed by the same letter are not significantly different based on Fisher's protected least significant difference test at $P \leq 0.05$.

\section{Discussion}

Lowering of $\psi_{\mathrm{S}}$ during drought contributes to enhanced drought tolerance because it maintains a favorable water status for plants with limited water availability (Zhou and $\mathrm{Yu}, 2010$ ). In this study, a greater reduction in $\psi_{\mathrm{S}}$ was observed in tall fescue receiving $60 \%$ ETo $\left(28.7 \%\right.$ lower $\left.\psi_{\mathrm{S}}\right)$ and $20 \%$ ETo (136.9\% lower $\psi_{\mathrm{S}}$ ) compared with $100 \%$ ETo treatment when data were averaged over three measurement dates. This finding is in agreement with previous reports (DaCosta and Huang, 2006; Qian and Fry, 1997). For example, Qian and Fry (1997) reported that when soil water content declined to $18 \%$ for tall fescue and $16 \%$ for warm-season grasses [i.e., zoysiagrass, bermudagrass, and buffalograss (Buchloe dactyloides)], $\psi_{\mathrm{S}}$ dropped rapidly. Eight to $15 \mathrm{~d}$ after irrigation was stopped, drought stress resulted in increased osmotic adjustment for both creeping bentgrass (Agrostis stolonifera) and velvet bentgrass (Agrostis canina) (DaCosta and Huang, 2006).

Decreased $\psi_{\mathrm{S}}$ is accompanied by the accumulation of sucrose. Morgan (1984) reported that the accumulation of solutes such as water-soluble carbohydrate [WSC (i.e., glucose, fructose, and sucrose)] is associated with active osmotic adjustment when plants are subjected to soil water deficits. DaCosta and Huang (2006) reported that creeping bentgrass plants osmotically adjusted to dehydration stress by accumulating WSC. Similarly, Jiang and Huang (2001) observed that drought-preconditioned kentucky bluegrass had $21 \%$ to $44 \%$ higher leaf WSC than nonpreconditioned plants. Spollen and Nelson (1994) found that sucrose content increased $258 \%$ in the leaf base of tall fescue when averaged over 78,102 , and $126 \mathrm{~h}$ after water was withheld. In our study, sucrose content was significantly higher than that of the well-watered plants at $100 \%$ ETo irrigation at $8 \mathrm{~d}$ of deficit irrigation treatments. Sucrose content under long-term deficit irrigation was not different from that in well-watered fall fescue. The early increase in sucrose content may be an adaptive response to a short-term water deficit, because the water deficit may induce a shift in the partitioning of carbon in favor of sucrose synthesis (Castrillo, 1992; Daie, 1988).
Sucrose phosphate synthase, SS, and AI are major enzymes involved in sucrose metabolism (Mendicino, 1960; Rufty and Huber, 1983). In this study, tall fescue subjected to the $20 \%$ and the $60 \%$ ETo treatment had a higher level of SPS activity than plants with the $100 \%$ ETo. This may indicate that the demand for sucrose as an osmotic solute activates SPS activity under drought stress conditions. Sucrose synthase catalyzes both sucrose synthesis and degradation. In the present study, SS was measured as an enzyme for sucrose synthesis. Our data indicated that short-term deficit irrigation at $60 \%$ or $20 \%$ ETo enhanced SS activity and reduced AI activity in tall fescue. The changes became more pronounced with prolonging treatment duration. The effects of water deficit on SS and AI have been reported in other species (Castrillo, 1992; Dorion et al., 1996; Naya et al., 2007). Castrillo (1992) reported that leaf SS activity for sucrose synthesis was greater when $P$. vulgaris plants were exposed to water deficit than when they were well-watered. However, Vassey et al. (1991) did not find a higher level of SS activity when $P$. vulgaris plants were subjected to water deficit. No changes in SS activity were observed in alfalfa (Medicago sativa) nodules subjected to a moderate drought (leaf water potential of $-1.3 \mathrm{MPa}$ ) (Naya et al., 2007). Acid invertase is involved in sucrose hydrolysis. In contrast to SS, AI activity in this study was reduced under long-term deficit irrigation. These results are similar to other studies. For example, at anthesis of wheat, AI activity in anthers from water-stressed plants was half that observed in well-watered controls (Dorion et al., 1996). Stancato et al. (2001) reported that activities of AI were reduced in leaves of drought-stressed epiphytic orchids (Cattleya forbesii $\times$ Laelia tenebrosa). These results implied that an increase in SS and a decrease in AI could partially contribute to the sucrose increase that occurred early in our experiment (before the first measurement day, $8 \mathrm{~d}$ after water was withheld). Kaur et al. (2007) reported higher sucrose content accompanied by a higher SPS and a lower AI and SS (in the cleavage direction) activities in wheat roots under water deficit, and this could be responsible for drought tolerance in wheat.

In summary, we demonstrated that tall fescue subjected to deficit irrigation generally exhibited a reduced $\mathrm{LWC}$ and $\psi_{\mathrm{S}}$ for tall fescue. Plants exposed to short-term $(8 \mathrm{~d})$ deficit irrigation had higher leaf sucrose content than well-irrigated controls. Higher sucrose levels in the leaves of water-stressed tall fescue might contribute to improved drought tolerance by decreasing $\psi_{\mathrm{S}}$ in leaves in response to prolonged periods of water stress. Sucrose phosphate synthase, SS, and AI enzymes play an important role in sucrose accumulation.

\section{Literature Cited}

Beard, J.B. 1973. Turfgrass: Science and culture. Prentice-Hall, Englewood Cliffs, New Jersey.

Castrillo, M. 1992. Sucrose metabolism in bean plants under water deficit. J. Expt. Bot. 43:1557-1561.

Cheikh, N. and M.L. Brenner. 1992. Regulation of key enzymes of sucrose biosynthesis in soybean leaves: Effect of dark and light conditions and role of gibberellins and abscisic acid. Plant Physiol. 100:1230-1237.

DaCosta, M. and B. Huang. 2006. Minimum water requirements for creeping, colonial, and velvet bentgrasses under fairway conditions. Crop Sci. 46:81-89.

Daie, J. 1988. Mechanism of drought-induced alterations in assimilate partitioning and transport in crops. CRC Crit. Rev. Plant Sci. 7:117-137.

Dernoeden, P.H. 2002. Creeping bentgrass management: Summer stresses, weeds, and selected maladies. Wiley, Hoboken, NJ. 
Dorion, S., S. Lalonde, and H.S. Saini. 1996. Induction of male sterility in wheat by meiotic stage water deficit is preceded by a decline in invertase activity and changes in carbohydrate metabolism in anthers. Plant Physiol. 111:137-145.

Fry, J. and B. Huang. 2004. Applied turfgrass science and physiology. Wiley, Hoboken, NJ.

Fu, J., J. Fry, and B. Huang. 2004. Minimum water requirements of four turfgrasses in the transition zone. HortScience 39:1740-1744.

Fu, J., J.D. Fry, and B. Huang. 2007. Growth and carbon metabolism of tall fescue and zoysiagrass as affected by deficit irrigation. HortScience 42:378-381.

Geigenberger, P., R. Reimholz, M. Geiger, L. Merlo, V. Canale, and M. Stitt. 1997. Regulation of sucrose and starch metabolism in potato tubers in response to short-term water deficit. Planta 201:502-518.

Gibeault, V.A., J.L. Meyer, V.B. Youngner, and S.T. Cockerham. 1985. Irrigation of turfgrass below replacement of evapotranspiration as a means of water conservation: Performance of commonly used turfgrasses. Intl. Turfgrass Soc. Res. J. 347-356.

Harn, C. and J. Daie. 1992. Regulation of the cytosolic fructose-1,6bisphosphatase by post-translational modification and protein level in drought-stressed leaves of sugarbeet. Plant Cell Physiol. 33:763-770.

Hawker, J.S. 1985. Sucrose, p. 1-50. In: Day, P.M. and R.A. Dixon (eds.). Biochemistry of storage carbohydrates in green plants. Academic Press, London, UK.

Hoagland, D.R. and D.I. Arnon. 1950. The water-culture method for growing plants without soil. California Agr. Expt. Sta. Cir. 347.

Huber, S.C. and J.L. Huber. 1992. Site specific serine phosphorylation of spinach leaf sucrose-phosphate synthase. Biochem. J. 283:877882.

Huber, S.C. and J.L. Huber. 1996. Role and regulation of sucrose phosphate synthase in higher plants. Annu. Rev. Plant Physiol. Plant Mol. Biol. 47:431-444.

Huber, S.C. and D. Israel. 1982. Biochemical basis for the partitioning of photosynthetically fixed carbon between starch and sucrose in soybean leaves. Plant Physiol. 69:691-696.

Jiang, Y. and B. Huang. 2001. Osmotic adjustment and root growth associated with drought preconditioning-enhanced heat tolerance in kentucky bluegrass. Crop Sci. 41:1168-1173.

Kaur, K., A.K. Gupta, and N. Kaur. 2007. Effect of water deficit on carbohydrate status and enzymes of carbohydrate metabolism in seedlings of wheat cultivars. Indian J. Biochem. Biophys. 44:223-230.

Keller, F. and M.M. Ludlow. 1993. Carbohydrate metabolism in drought stressed leaves of pigeonpea (Cajanus cajan). J. Expt. Bot. 44:1351-1359.

Khayat, E. and Z. Zieslin. 1987. Effect of night temperature on the activity of sucrose phosphate synthase, acid invertase, and sucrose synthase in source and sink tissues of Rosa hybrida cv Golden Times. Plant Physiol. 84:447-449.

Liu, X. and B. Huang. 2000. Carbohydrate accumulation in relation to heat stress tolerance in two creeping bentgrass cultivars. J. Amer. Soc. Hort. Sci. 125:442-447.

McManus, M.T., R.L. Bieleski, J.R. Caradus, and D.J. Barker. 2000. Pinitol accumulation in mature leaves of white clover in response to a water deficit. Environ. Exp. Bot. 43:11-18.

Mendicino, J. 1960. Sucrose phosphate synthesis in wheat germ and green leaves. J. Biol. Chem. 235:3347-3352.
Morgan, J.M. 1984. Osmoregulation and water stress in higher plants. Annu. Rev. Plant Physiol. 35:299-319.

Naya, L., R. Ladrera, J. Ramos, E.M. Gonzalez, C. Arrese-Igor, F.R. Minchin, and M. Becana. 2007. The response of carbon metabolism and antioxidant defenses of alfalfa nodules to drought stress and to the subsequent recovery of plants. Plant Physiol. 144:1104-1114.

Premachandra, G.S., H. Aneoka, H. Fujita, and S. Ogata. 1992. Leaf water relations, osmotic adjustment, cell membrane stability, epicuticular wax load and growth as affected by increasing water deficit in sorghum. J. Expt. Bot. 43:1569-1576.

Qian, Y.L. and J.D. Fry. 1997. Water relations and drought tolerance of four turfgrasses. J. Amer. Soc. Hort. Sci. 122:129-133.

Rekika, D., M.M. Nachit, J.L. Araus, and P. Monneveus. 1998. Effects of water deficit on photosynthetic rate and osmotic adjustment in tetraploid wheats. Photosynthetica 35:129-138.

Rocher, J.P., S.L. Prioul, A. Leehamy, A. Reyss, and M. Joussaume. 1989. Genetic variability in carbon fixation, sucrose-P synthase and ADP-glucose pyrophosphorylase in maize plants of differing growth rate. Plant Physiol. 89:416-420.

Rufty, T.W., Jr and S.C. Huber. 1983. Changes in starch formation and activities of sucrose phosphate synthase and cytoplasmic fructose1,6-bisphosphatase in response to source-sink alterations. Plant Physiol. 72:474-480.

Spollen, W.G. and C.J. Nelson. 1994. Response of fructan to water deficit in growing leaves of tall fescue. Plant Physiol. 106:329-336.

Stancato, G.C., P. Mazzafera, and M.S. Buckeridge. 2001. Effect of a drought period on the mobilization of non-structural carbohydrates, photosynthetic efficiency and water status in an epiphytic orchid. Plant Physiol. Biochem. 39:1009-1016.

Stitt, M., I. Wilke, R. Feil, and H.W. Heldt. 1988. Coarse control of sucrose phosphate synthase in leaves: Alterations of the kinetic properties in response to the rate of photosynthesis and the accumulation of sucrose. Planta. 174:217-230.

Sumner, J.B. 1925. A more specific reagent for the determination of sugar in urine. J. Biol. Chem. 65:393-395.

Tan, W.X., T.J. Blake, and T.B. Boyle. 1992. Drought tolerance in faster and slower growing black spruce (Picea mariana) progenies: II. Osmotic adjustment and changes of soluble carbohydrate and amino acids under osmotic stress. Plant Physiol. 85:645-651.

Ting, S.V. 1956. Rapid calorimetric methods for simultaneous determination of total reducing sugars and fructose in citrus juices. J. Agr. Food Chem. 4:263-266.

Turgeon, A.J. 2008. Turfgrass management. 8th Ed. Pearson Prentice Hall, Upper Saddle River, NJ.

Vassey, T.L., P. Quick, T.D. Sharkey, and M. Stitt. 1991. Water stress, carbon dioxide, and light effect on sucrose phosphate synthase activity in Phaseolus vulgaris. Physiol. Plant. 81:37-44.

Yang, J., J. Zhang, Z. Wang, Q. Zhu, and L. Liu. 2001. Water deficit induced senescence and its relationship to the remobilization of prestored carbon $n$ wheat during grain filling. Agron. J. 93:196-206.

Zhang, B. and D.D. Archbold. 1993. Solute accumulation in leaves of a Fragaria chiloensis and $F$. virginiana selection responds to water deficit stress. J. Amer. Soc. Hort. Sci. 118:280-285.

Zhou, Q. and Y.J. Yu. 2010. Changes in content of free, conjugated and bound polyamines and osmotic adjustment in adaptation of vetiver grass to water deficit. Plant Physiol. Biochem. 48:417-425. 